\title{
Fabrication of ultrafine manganese oxide-decorated carbon nanofibers for
}

\section{high-performance electrochemical capacitors}

Ying Yang,,${ }^{\mathrm{a}}$, Sungsik Lee, ${ }^{\mathrm{b}}$ Dennis E. Brown, ${ }^{\mathrm{c}}$ Hairui Zhao, ${ }^{\mathrm{a}}$ Xinsong Li, ${ }^{\mathrm{a}}$ Daqiang Jiang, ${ }^{\mathrm{a}}$ Shijie Hao, ${ }^{\mathrm{a}}$ Yongxiang Zhao, ${ }^{\mathrm{a}}$ Daoyong Cong, ${ }^{\mathrm{d}}$ Xin Zhang,,${ }^{\mathrm{a},}$ Yang Ren ${ }^{\mathrm{b}}$

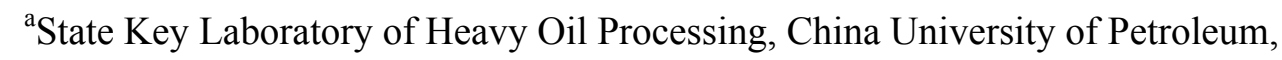
Changping, Beijing 102249, China

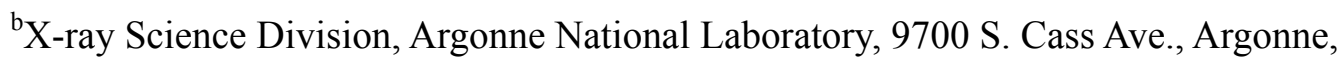
Illinois 60439, USA

${ }^{c}$ Department of Physics, Northern Illinois University, De Kalb, Illinois 60115, USA

${ }^{\mathrm{d}}$ State Key Laboratory for Advanced Metals and Materials, University of Science and Technology Beijing, No. 30 Xueyuan Rd, Haidian District, Beijing 100083, China

To whom correspondence should be addressed: Dr. Ying Yang

Postal address: No.18, Fuxue Road, Changping District, Beijing, P.R. China

Postcode: 102249

Tel./fax: $+86-10-89734979$

E-mail address: catalyticscience@ 0 163.com 
Abstract Ultrafine manganese oxide-decorated carbon nanofibers $\left(\mathrm{MnO}_{\mathrm{n}}-\mathrm{CNF}, 1.3<\right.$ $\mathrm{n}<2.0)$ as a new type of electrode materials are facilely fabricated by direct conversion of $\mathrm{Mn}$, Zn-trimesic acid $\left(\mathrm{H}_{3} \mathrm{BTC}\right)$ metal organic framework fibers (Mn-ZnBTC). The construction and evolution of Mn-ZnBTC fibers are investigated by SEM and in situ high-energy XRD. The manganese oxides are highly dispersed onto the porous carbon nanofibers formed simultaneously, verified by TEM, X-ray absorption fine structure (XAFS), Raman, ICP-AES and $\mathrm{N}_{2}$ adsorption techniques. As expected, the resulting $\mathrm{MnO}_{\mathrm{n}}-\mathrm{CNF}$ composites are highly stable, and can be cycled up to 5000 times with a high capacitance retention ratio of $98 \%$ in electrochemical capacitor measurements. They show a high capacitance of up to $179 \mathrm{~F} \mathrm{~g}^{-1}$ per mass of the composite electrode, and a remarkable capacitance of up to $18290 \mathrm{~F} \mathrm{~g}^{-1}$ per active mass of the manganese(IV) oxide, significantly exceeding the theoretical specific capacitance of manganese(IV) oxide $\left(1370 \mathrm{~F} \mathrm{~g}^{-1}\right)$. The maximum energy density is up to $19.7 \mathrm{Wh} \mathrm{kg}^{-1}$ at the current density of $0.25 \mathrm{~A} \mathrm{~g}^{-1}$, even orders higher than those of reported electric double-layer capacitors and pseudocapacitors. The excellent capacitive performance can be ascribed to the joint effect of easy accessibility, high porosity, tight contact and superior conductivity integrated in final $\mathrm{MnO}_{\mathrm{n}}-\mathrm{CNF}$ composites.

Keywords: Manganese oxide; Carbon nanofiber; Assembly; In situ synthesis; Supercapacitor 


\section{Introduction}

The increasing demand on environmentally benign, high-performance energy-storage systems has stimulated intense research interest in areas such as batteries and capacitors [1]. Supercapacitors have emerged as one of the most promising candidates for energy storage as they can provide a higher power density than batteries, and a higher energy density than conventional dielectric capacitors. And thereby their applications are widely shown in consumer electronics, energy management, memory back-up system, industrial power and mobile electrical systems [2]. To be competent for these applications, the improvement of the capacitive performance, as well as the decrease of the fabrication cost for electrode materials, is the essential criteria. In the search for appropriate materials for supercapacitor electrodes, various carbons, conducting polymers and transition metal oxides have been extensively investigated [3]. Among them, the manganese oxides prove to be promising for next generation supercapacitors owing to its low cost, environmental compatibility and high specific capacitance [4]. However, the capacitance of manganese oxides cannot be achieved intrinsically due to their large size and poor dispersion, and they usually suffer from inferior stability, low conductivity and large volume change during the charge/discharge processes. To overcome these drawbacks, fabrication of ultrafine manganese oxides and combination of them with porous carbons would be the solution.

Among various carbonaceous materials, one-dimensional (1D) nanostructured 
carbon nanofibers (CNF) exhibit superior thermal and electrical conductivity, and shorter diffusion paths for electrons and ions during the electrochemical process [5]. And therefore the metal oxide composites based on the strengthened carbon nanofibers have been widely investigated. Recent advances in the fabrication of metal oxide-carbon nanofiber composites focus on a post-synthetic procedure, in which the carbon nanofibers are pre-synthesized by a chemical vapor deposition (CVD), catalytic CVD (CCVD) or electrospinning method, followed by impregnation and reduction of metal salts [6-8]. Such a tedious synthesis renders loosely attached metal oxides, which are randomly distributed on the external surface or near the pore mouth, eroding the reactivity and stability of composite materials finally. To replace such "low efficient" preparations, pyrolysis of electrospun fibers within metal and carbon precursors proves to be effective to construct evenly dispersed metal oxides firmly attached onto the carbon nanofibers [9-10]. However, the resulting composites often possess an extremely low surface area and porosity, though some pore-forming reagents, including surfactants and silica assistants, are often involved [11-13], which largely limits the power capacity. Facile fabrication of high-performance ultrafine metal oxide-carbon nanofiber composites still remains challenging.

Herein, we report ultrafine manganese oxide-decorated carbon nanofibers $\left(\mathrm{MnO}_{\mathrm{n}}-\mathrm{CNF}\right)$ as a new type of electrode materials fabricated by a facile synthesis. By optimizing the assembly time, Mn, Zn-containing metal organic framework fibers were skillfully constructed by assembly of $\mathrm{MnCl}_{2} \cdot 4 \mathrm{H}_{2} \mathrm{O}$ and $\mathrm{Zn}(\mathrm{Ac})_{2} \cdot 2 \mathrm{H}_{2} \mathrm{O}$ and trimesic acid $\left(\mathrm{H}_{3} \mathrm{BTC}\right)$ in the presence of $\mathrm{N}, \mathrm{N}$-dimethylformamide (DMF), and were 
then directly converted to $\mathrm{MnO}_{\mathrm{n}}-\mathrm{CNF}$ after pyrolysis. This facile fabrication integrates some merits, including easy accessibility, high porosity, tight contact and superior conductivity in final $\mathrm{MnO}_{\mathrm{n}}-\mathrm{CNF}$ composites. And thus the $\mathrm{MnO}_{\mathrm{n}}-\mathrm{CNF}$

composites exhibit an ultra-high specific capacitance up to $18290 \mathrm{~F} \mathrm{~g} \mathrm{~g}^{-1}$ per active mass of manganese(IV) oxide, and can be cycled up to 5000 times with a high capacitance retention ratio of $98 \%$ during the electrochemical capacitor test. Meanwhile, the high energy density are comparable to or higher than high-end commercially available supercapacitors. These results demonstrate that the $\mathrm{MnO}_{\mathrm{n}}-\mathrm{CNF}$ composite exhibits great potentials as an efficient electrode material for supercapacitors.

\section{Experimental section}

2.1. Preparation of manganese oxide-decorated carbon nanofibers.

$\mathrm{MnCl}_{2} \cdot 4 \mathrm{H}_{2} \mathrm{O}, \mathrm{Zn}(\mathrm{Ac})_{2} \cdot 2 \mathrm{H}_{2} \mathrm{O}$ and $\mathrm{H}_{3} \mathrm{BTC}$ were used as precursors for the synthesis of Mn, Zn-containing metal organic framework fibers in the presence of DMF. The molar ratio of the precursor mixture used in the preferred preparation is 6 $\mathrm{H}_{3} \mathrm{BTC}: 5(1-\mathrm{x}) \mathrm{Zn}(\mathrm{Ac})_{2} \cdot 2 \mathrm{H}_{2} \mathrm{O}: 5 \mathrm{x} \mathrm{MnCl}_{2} \cdot 4 \mathrm{H}_{2} \mathrm{O}: 650 \mathrm{DMF}$, where $\mathrm{x}$ represents the Mn molar percentage in total metals of $\mathrm{Mn}$ and $\mathrm{Zn}$ in the synthetic mixture, and was set to be $0,0.025,0.050,0.100$ and $0.500 \%$. Typically, a certain amount of metal salts combined with $1.25 \mathrm{~g}$ of $\mathrm{H}_{3} \mathrm{BTC}$ were dissolved in $50 \mathrm{~mL}$ of DMF under constant agitation, and were then solvothermally treated at $140{ }^{\circ} \mathrm{C}$ for $750 \mathrm{~min}$. The resulting precipitate was collected after decanting the mother liquor, rinsing with DMF and drying under vacuum, and was denoted as 100xMn-ZnBTC. Then the 
$100 x M n-Z n B T C$ fiber was placed in a quartz boat, flushing with $\mathrm{N}_{2}$ flow, and heated in a tube furnace up to $950{ }^{\circ} \mathrm{C}$ at a rate of $5^{\circ} \mathrm{min}^{-1}$ and maintained at this temperature for $2 \mathrm{~h}$, yielding the manganese oxide-carbon nanofiber composite, $100 \mathrm{xMnO}_{\mathrm{n}}-\mathrm{CNF}$. In addition, the post-synthetic $0.100 \mathrm{MnO}_{\mathrm{n}}-\mathrm{CNF}-\mathrm{p}$ and mechanically mixed $0.100 \mathrm{MnO}_{2}+\mathrm{CNF}$ were also prepared for comparison (Supporting Information).

\subsection{Characterization}

SEM analysis was performed on a FEI-Quanta 200F field-emission scanning microscope operated at $15 \mathrm{kV}$ with an EDS detector. The TEM images, selected area electron diffraction (SAED) patterns, high angle annular dark field scanning TEM (HAADF-STEM) images and elemental maps were recorded using a FEI Tecnai G2 F20 transmission electron microscope equipped with an energy dispersive X-ray spectroscopic analyzer operated at a voltage of $200 \mathrm{kV}$. Samples were sonicated in $\mathrm{EtOH}$ for $5 \mathrm{~min}$, and one drop of the suspended sample was dripped in a holely carbon microgrid supported on a 300 mesh copper grid. $\mathrm{N}_{2}$ adsorption/desorption isotherms were recorded at $77 \mathrm{~K}$ using a JW-BK222 static volumetric gas adsorption instrument manufactured by Beijing JWCB Sci. \& Tech. Co., Ltd. Before measurements, the samples were de-gassed at $300{ }^{\circ} \mathrm{C}$ for $3 \mathrm{~h}$ in vacuum. The specific surface area was determined by using the Brunauer-Emmett-Teller (BET) method and the mesopore size distribution was measured by using the Barrett-Joyner-Halenda (BJH) method from the desorption branch of the isotherms. In situ synchrontron X-ray diffraction measurements were performed at the 11-ID-C beamline of the Advanced Photon Source (APS) at Argonne National Laboratory. High-energy X-rays 
of $115 \mathrm{KeV}$ energy and $0.6 \mathrm{~mm} \times 0.6 \mathrm{~mm}$ beam size were used to obtain two-dimensional (2D) diffraction patterns in the transmission geometry using a Perkin-Elmer large area detector placed at $1.6 \mathrm{~m}$ from the sample. X-ray absorption fine structure (XAFS) was carried out on the 12-BM-B beamline of APS at Argonne National Laboratory. The XAFS data were obtained in the fluorescence mode at the Mn K-edge (6539.0 eV). The XAFS data were processed using the Athena software for background removal, post-edge normalization and X-ray absorption near edge structure (XANES) analysis. The oxidation states were determined by comparing the inflection point of the edge to that of standards with a known oxidation state. The extended X-ray absorption fine structure (EXAFS) was analyzed using Artemis software, which implemented FEFF. The EXAFS data reduction was conducted by utilizing the standard procedures. The EXAFS function, $\chi$, was obtained by subtracting the post-edge background from the overall absorption and then normalized with respect to the edge jump step. Subsequently, $\mathrm{k}^{3}$-weighted $\chi(\mathrm{k})$ data in $\mathrm{k}$ space were Fourier transformed to those in $r$ space to separate the EXAFS contributions from different coordination shells. However, fitting the Mn local structure was not sucessful because the error of coordination numbers is always larger than $10 \%$. Raman spectra were recorded using a HORIBA Jobin Yvon HR800 instrument with a microscope attachment. A laser wavelength of $633 \mathrm{~nm}$ wavelength was focused using a diffraction limited spot, and the scan time was $2 \mathrm{~s}$ for each sample.

The Mn dosage was estimated by inductively coupled plasma-atomic emission spectroscopy (ICP-AES) analysis conducted on a Perkin Elmer emission spectrometer. 
Certain amount of vacuum-dried sample was placed in a crucible and heated at $600{ }^{\circ} \mathrm{C}$ for $8 \mathrm{~h}$ in air. The residue was then dissolved in $3 \mathrm{~mL}$ of aqua fortis solution, and each solution was filtered through a $0.45 \mu \mathrm{m}$ polyethersulfone filter and set the constant volume to be $10 \mathrm{~mL}$, and then submitted for analysis.

\subsection{Electrochemical test}

Electrochemical measurements were performed via a conventional three-electrode system in a $6 \mathrm{M} \mathrm{KOH-distilled} \mathrm{water} \mathrm{electrolyte,} \mathrm{which} \mathrm{were}$ performed using a CHI660D electrochemical workstation. The $\mathrm{Hg} / \mathrm{Hg}_{2} \mathrm{Cl}_{2}$ electrode was used as a reference electrode, and $\mathrm{Pt}$ as a counter electrode. The working electrode slurries containing the $\mathrm{MnO}_{\mathrm{n}}-\mathrm{CNF}$ composite synthesized, acetylene black and polytetrafluorethylene at a weight ratio of 7:2:1 were painted on a nickel foam for electrochemical characterization. The Ni foam has a surface area of $1 \mathrm{~cm}^{2}$ and then the pressure of $3 \mathrm{MPa}$ was applied. The electrochemical properties were tested by cyclic voltammetry $(\mathrm{CV})$ and galvanostatic charge-discharge (the potential window in the range of -1.0 to $0 \mathrm{~V}$ versus $\mathrm{Hg} / \mathrm{Hg}_{2} \mathrm{Cl}_{2}$ electrode), and electrochemical impedance spectroscopy (frequency range between $1 \mathrm{mHz}$ and $10^{3} \mathrm{kHz}$ ). The electrochemical specific capacitance $\left(\mathrm{C}_{\mathrm{m}}\right)$ of the electrode material was determined as follows:

$$
C_{m}=\frac{C}{m}=\frac{S}{2 U V m}
$$

in which $\mathrm{C}_{\mathrm{m}}$ is the gravimetric specific capacitance of electrode material $\left(\mathrm{F} \mathrm{g} \mathrm{g}^{-1}\right), \mathrm{C}$ is the capacitance $(\mathrm{F}), \mathrm{m}$ is the mass of electrode material $(\mathrm{g}), \mathrm{S}$ is the integrated area of the $\mathrm{CV}$ curve, $\mathrm{V}$ is the scan rate $\left(\mathrm{mV} \mathrm{s}^{-1}\right)$ and $\mathrm{U}$ is the potential window $(\mathrm{V})$. The 
pseudocapacitance due to the managanese(IV) oxide $\left(\mathrm{C}_{\mathrm{MnO} 2}\right)$ in the composite has been calculated by subtracting the electrochemical double layer capacitor (EDLC) capacitance contributed by the pure CNF substrate according to the following equation:

$$
\mathrm{C}_{\mathrm{MnO}_{2}}=\left(\mathrm{C}_{\mathrm{m}}-\mathrm{C}_{\mathrm{c}} \times \mathrm{C} \%\right) / \mathrm{Mn} \%
$$

Where $\mathrm{C}_{\mathrm{c}}$ is the specific capacitance of pure $\mathrm{CNF}$, and $\mathrm{C} \%$ and $\mathrm{Mn} \%$ are the weight percentages of $\mathrm{CNF}$ and $\mathrm{MnO}_{2}$ in the composites.

The energy density and power density were estimated, using the following equations:

$$
\begin{gathered}
\mathrm{E}=\frac{1}{2} \times \mathrm{C}_{\mathrm{m}} \times(\Delta \mathrm{V})^{2} \\
\mathrm{P}=\frac{\mathrm{E}}{\Delta \mathrm{t}}
\end{gathered}
$$

where $\Delta \mathrm{V}(\mathrm{V})$ refers to the potential change within the discharge time $\Delta \mathrm{t}(\mathrm{s}), \mathrm{E}\left(\mathrm{J} \mathrm{g}^{-1}\right)$ refers to the energy density, $\mathrm{P}\left(\mathrm{W} \mathrm{g}^{-1}\right)$ corresponds to the average power density.

\section{Results and discussion}

\subsection{Synthesis}

The schematic diagram in Fig. 1 shows the preparation process of $\mathrm{MnO}_{\mathrm{n}}-\mathrm{CNF}$ composites. To illustrate the growth progress of $\mathrm{Mn}, \mathrm{Zn}$-containing metal organic framework fibers (Mn-ZnBTC), SEM was employed to monitor the time-dependant morphology of the representative $0.100 \mathrm{Mn}-\mathrm{ZnBTC}(0.100 \%$ of Mn molar percentage). In terms of uniform hexagonal plates crystals (seed crystals, 1 min) displayed in Fig. 2, the size of these plates increases when the reaction time is prolonged to $5 \mathrm{~min}$. When the reaction is procedded for 10-60 min, these plates become smooth and compact, 
and their size is further increased. As the reaction time is extended to $240 \mathrm{~min}$, prism-like fibers with a length of up to $10 \mu \mathrm{m}$ start to form, originated from the piled hexagonal plates along the (100) direction. However, these hexagonal plates are loosely connected because the gap between two plates exists. Longer fibers are produced as the reaction time is extended to $480 \mathrm{~min}$, and the hexagonal cross-section is transformed to a circular one. Based on these observations, the initially formed $2 \mathrm{D}$ hexagonal plates are stacked up to 1D fibers, and further grow into smooth and uniform fibers when prolonging the reaction time. So in our experiment, the Mn-ZnBTC fibers were successfully constructed by assembly of metal salts with $\mathrm{H}_{3} \mathrm{BTC}$ struts in DMF for $750 \mathrm{~min}$. And then one-pot conversion was employed to transform Mn-ZnBTC fibers to $\mathrm{MnO}_{\mathrm{n}}-\mathrm{CNF}$ composites under $\mathrm{N}_{2}$ atmosphere (Fig. 1).

To determine the proper temperature for this one-pot conversion, the transformation of Mn-ZnBTC fibers during pyrolysis was investigated by in situ high-energy X-ray diffraction (XRD) study. As illustrated in Fig. 3a, the starting material displays a set of rutile-structured $\left(\mathrm{P}_{2} / \mathrm{mnm}\right)$ diffractions in the $2 \theta$ range of $0.3-3^{\circ}[14]$. These diffractions become weak at $150{ }^{\circ} \mathrm{C}$, indicating the initial decomposition occurred. And they are completely vanished at $c a .500{ }^{\circ} \mathrm{C}$, suggesting the decomposition was completed. At $500{ }^{\circ} \mathrm{C}$, the graphitic carbon starts to form (JCPDS No. 41-1487), showing the characteristic diffractions at $0.4^{\circ}$ [15]. Meanwhile, the wurtzite $\mathrm{ZnO}$ (JCPDS No. 36-1451) is initially formed, showing a series of diffractions ranging from $2.0^{\circ}$ to $4.5^{\circ}[16]$, represented by the filled cycles (Fig. 3b). The increased intensity below $700{ }^{\circ} \mathrm{C}$ indicates more $\mathrm{ZnO}$ formed, while the decreased 
intensity above $700{ }^{\circ} \mathrm{C}$ implies the reduction of $\mathrm{ZnO}$ to metallic $\mathrm{Zn}$ and its further volatilization occurred (Fig. 3a). A fraction of $\mathrm{ZnO}$ still remains because the rapid cooling was employed once the temperature reaches to $950{ }^{\circ} \mathrm{C}$, which can be completely removed by prolonging the pyrolysis time. It is noteworthy that the lattice parameters of $\mathrm{ZnO}$ are temperature dependent, and the increase in temperature leads to the expansion of lattice (Fig. 3b), as reported by Banerjee and coworkers [17]. Moreover, the manganese oxides, mainly $\mathrm{Mn}_{3} \mathrm{O}_{4}$ and $\mathrm{MnO}_{2}$ (unified into $\mathrm{MnO}_{\mathrm{n}}, 1.3<$ $\mathrm{n}<2.0$ ), start to emerge at $c a .650{ }^{\circ} \mathrm{C}$, as illustrated by the presence of diffraction peaks of $\mathrm{Mn}_{3} \mathrm{O}_{4}$ (JCPDS No. 24-0734) at $2.5^{\circ}$ and $\mathrm{MnO}_{2}$ (JCPDS No. 44-0141) at 3.2 $2^{\circ}$, $3.8^{\circ}$ and $4.5^{\circ}[18]$. The intensity of these diffraction peaks increases as the temperature was elevated from 650 to $950{ }^{\circ} \mathrm{C}$ (Fig. 3b), implying the growth of manganese oxides. Based on these investigations, the strategy of pyrolysis at $950{ }^{\circ} \mathrm{C}$ for $2 \mathrm{~h}$ was carried out to transform $\mathrm{Mn}-\mathrm{ZnBTC}$ fibers to $\mathrm{MnO}_{\mathrm{n}} \mathrm{CNF}$ composites. This fabrication is quite facile without the need of expensive apparatus or the assistance of pore-forming reagents and extra carbon precursors.

The above results help us understand the fabrication process for $\mathrm{MnO}_{\mathrm{n}}-\mathrm{CNF}$ composites. First, $\mathrm{Mn}^{2+}$ and $\mathrm{Zn}^{2+}$ ions coordinated with $\mathrm{H}_{3} \mathrm{BTC}$ struts in the presence of DMF, and they assembled into 2D hexagonal plates and then were stacked up into 1D fibers under solvothermal conditions. During the assembly process, the fibrous morphology and the metal dispersion are preset in the Mn-ZnBTC fibers. The following high-temperature pyrolysis at $950{ }^{\circ} \mathrm{C}$ is a unique "one stone, three birds" strategy for transformation of $\mathrm{Mn}-\mathrm{ZnBTC}$ fibers to $\mathrm{MnO}_{\mathrm{n}}-\mathrm{CNF}$ composites. Gradual 
loss of hydrogen, oxygen and carbon occurred when heated, and the $\mathrm{H}_{3} \mathrm{BTC}$ struts were converted to inorganic carbons. The anchored Mn species, which bind several oxygens from $\mathrm{H}_{3} \mathrm{BTC}$ structs, were in situ reduced in the presence of the liberated gas $\left(\mathrm{H}_{2}, \mathrm{CO}\right.$, etc. $)$ and the formed carbon, yielding manganese oxides $\left(\mathrm{MnO}_{\mathrm{n}}\right)$. Meanwhile, the in situ formed $\mathrm{ZnO}$ acted as a template to consolidate the carbonaceous network, which was reduced to $\mathrm{Zn}$ metal above $700{ }^{\circ} \mathrm{C}$ in the presence of carbon, and was then removed when heated to $908{ }^{\circ} \mathrm{C}$ (b.p. of $\mathrm{Zn}$ ). It is worth mentioning that $\mathrm{Zn}^{2+}$ species are more inclined to reduce than $\mathrm{Mn}^{2+}$ species, because $\mathrm{Zn}^{2+} / \mathrm{Zn}$ has a higher electrode potential $(-0.7618 \mathrm{eV})$ than $\mathrm{Mn}^{2+} / \mathrm{Mn}(-1.185 \mathrm{eV})$. In this case, $\mathrm{ZnO}$ is easily reduced to $\mathrm{Zn}$, while the formed maganese oxide remains. Moreover, the vaporization of $\mathrm{Zn}$ metals, and the decomposition of crystalline MOFs would create carbon nanofibers within high porosity.

\subsection{SEM and TEM studies}

SEM and TEM observations were first employed to verify the formation of $\mathrm{Mn}-\mathrm{ZnBTC}$ fibers, which is the prerequisite to fabricate $\mathrm{MnO}_{\mathrm{n}}-\mathrm{CNF}$ composites. As illustrated in Fig. 4a, the SEM image of representative $0.100 \mathrm{Mn}-\mathrm{ZnBTC}$ exhibits uniform fibers, and displays an average diameter of $c a .100 \mathrm{~nm}$ and a length of 5-10 $\mu \mathrm{m}$. These fibers have a prism-like shape, showing some defects on the surface (Fig. 4b). TEM, HAADF-STEM and elemental maps show that these fibers are stuffed (Fig. 4c) and uniform (Fig. 4d), and C, O, Zn and Mn elements are evenly distributed throughout the whole fiber (Fig. 4e), further confirming that the formed $0.100 \mathrm{Mn}-\mathrm{ZnBTC}$ fibers are homogeneous. It is noteworthy that $\mathrm{O}$ and $\mathrm{Zn}$ elements 
are more dense, in accordance with the SEM-EDX result (Fig. S1), suggesting the predominance of $\mathrm{Zn}_{4} \mathrm{O}$ secondary building units in $0.100 \mathrm{Mn}-\mathrm{ZnBTC}$ fibers. By varying the $\mathrm{Mn}$ molar percentage in the range of $0.025-0.500 \%$, different $\mathrm{Mn}$, Zn-containing metal organic framework fibers can be synthesized, showing essentially similar appearance and dimensions (Fig. S2a-d) to $0.100 \mathrm{Mn}-\mathrm{ZnBTC}$. They are well separated without agglomeration, and have lengths ranging from several to tens of micrometers and diameters from tens to several hundred nanometers.

Being pyrolyzed, the parent fibrous morphology is inherited in the resulting $0.100 \mathrm{MnO}_{\mathrm{n}}-\mathrm{CNF}$ composite (Fig. 4f). However, these fibers are slightly contracted, and their cross-sections are fluffy (Fig. 4g). No aggregation can be observed, implying a well-dispersed configuration. TEM observation reveals that these nanofibers display a dark and bright appearance, and are intercrossed into a web (Fig. 4h). The HAADF-STEM image of a single nanofiber shows that the surface is rugged, and the manganese oxides are hardly observed (Fig. 4i), though the elemental maps demonstrate the presence of evenly distributed Mn species (Fig. 4j). The above observations lead to a tentative postulation that the Mn species were inserted into the carbon nanofiber in the form of ultrafine $\mathrm{MnO}_{\mathrm{n}}$. High-magnification TEM image shows the nanonodules $(\mathrm{ca} .5 \mathrm{~nm})$ are periodically distributed on the carbon nanofiber network (Fig. 4k), implying that the tiny $\mathrm{MnO}_{\mathrm{n}}$ particles are interconnected. However, only bright diffraction rings assigned to graphitic carbons (Fig. 4l) are shown in the selected area electron diffraction (SAED) pattern $[19,20]$, further confirming the formation of ultrafine $\mathrm{MnO}_{\mathrm{n}}$. Other Mn-ZnBTC fiber derived $\mathrm{MnO}_{\mathrm{n}}-\mathrm{CNF}$ composites 
also show similar appearance and dimensions (Fig. S2e-h) to $0.100 \mathrm{MnO}_{\mathrm{n}}-\mathrm{CNF}$. This suggests that the $\mathrm{MnO}_{\mathrm{n}}-\mathrm{CNF}$ composites can be successfully fabricated from Mn-ZnBTC fibers by tailoring the Mn molar percentage ranging from 0.025 to $0.500 \%$.

\subsection{XAFS study}

To further reveal the formation of ultrafine $\mathrm{MnO}_{\mathrm{n}}$, the elemental specific X-ray absorption fine structure (XAFS) was employed to investigate the transition and local structure of $\mathrm{Mn}$ species. The $\mathrm{Mn}$ dosage in final $\mathrm{MnO}_{\mathrm{n}}-\mathrm{CNF}$ composites is ultra-low, estimated to be $0.09-1.36 \mathrm{wt} \%$ by ICP-AES analysis (Table S1). Investigation of such low concentrated $\mathrm{Mn}$ species is extremely difficult using lab characterization techniques. XAFS can be competent for this analysis profiting from high flux and intensity of synchrotron radiation light. As illustrated in Fig. 5A, the $0.100 \mathrm{Mn}-\mathrm{ZnBTC}$ precursor exhibit a extremely strong white line intensity as compared to $\mathrm{MnCl}_{2} \cdot 4 \mathrm{H}_{2} \mathrm{O}$ and $\mathrm{MnO}_{2}$ standards, implying that the introduced $\mathrm{Mn}^{2+}$ species bind to several oxygens from $\mathrm{H}_{3} \mathrm{BTC}$ struts, corresponding to the coordination of $\mathrm{O} \rightarrow \mathrm{Mn}$. When pyrolysis, the resulting $0.100 \mathrm{MnO}_{\mathrm{n}}-\mathrm{CNF}$ composite exhibits a pre-edge feature and a negative shift in the adsorption edge position as compared to $0.100 \mathrm{Mn}-\mathrm{ZnBTC}$, suggesting that the Mn species are mostly reduced after pyrolysis. These reduced species still carry some positive charges because the edge position shifted positively as compared to that of Mn foil [21]. And the positive charges are larger than +2 , since $0.100 \mathrm{MnO}_{\mathrm{n}}-\mathrm{CNF}$ shows a stronger white line intensity than $\mathrm{MnCl}_{2} \cdot 4 \mathrm{H}_{2} \mathrm{O}$. Fig. 5B shows the radial distribution curves obtained by Fourier 
transformation of the $\mathrm{k}^{3} \chi(\mathrm{k})$ EXAFS spectra. The $0.100 \mathrm{MnO}_{\mathrm{n}}-\mathrm{CNF}$ composite shows one prominent peak at $1.3 \AA$ from Mn-O pairs and an additional peak at $2.6 \AA$ from Mn-Mn contributions [22], confirming the formation of manganese oxides. The observation that the $\mathrm{Mn}-\mathrm{O}$ bonding distance is close to that in $\mathrm{MnO}_{2}$ suggests the strong metal-support interaction, linking to the tight contact between $\mathrm{MnO}_{\mathrm{n}}$ and CNF.

\subsection{Raman spectroscopy}

The amount of graphitic carbons is the indication of conductivity of $\mathrm{MnO}_{\mathrm{n}}-\mathrm{CNF}$ composites, which affects the electrochemical performance significantly. So Raman spectroscopy was performed to investigate the local structure of carbons (Fig. 6). In the first order Raman spectra of the $\mathrm{sp}^{2}$-carbons, two conspicuous peaks emerge at approximately $1321 \mathrm{~cm}^{-1}$ (D band) and $1591 \mathrm{~cm}^{-1}$ (G band), arising from the disordered carbon structures and the vibration mode to the movement in opposite directions of two carbon atoms in a single graphene sheet [23]. It is generally accepted that the integral area ratio of the "G band" to the "D band" $\left(I_{G} / I_{D}\right)$ is the indication of graphitization degree. The $0.100 \mathrm{MnO}_{\mathrm{n}}-\mathrm{CNF}$ shows a largest $\mathrm{I}_{\mathrm{G}} / \mathrm{I}_{\mathrm{D}}$ value of 0.372 (Table S1), implying the existence of most graphitic components in the carbonaceous network. The variation of $\mathrm{I}_{\mathrm{G}} / \mathrm{I}_{\mathrm{D}}$ value demonstrates the role of $\mathrm{Mn}$ dosage on the conductivity of $\mathrm{MnO}_{\mathrm{n}}-\mathrm{CNF}$ composites.

\section{5. $\mathrm{N}_{2}$ adsorption study}

Low temperature $\mathrm{N}_{2}$ adsorption was performed to reveal the pore structure. An IV type isotherm with a distinct $\mathrm{H}_{4}$ type hysteresis loop is observed for both pure CNF and $\mathrm{MnO}_{\mathrm{n}}-\mathrm{CNF}$ composites (Fig. 7A), implying the mesoporous arrays within slit 
pores $[24,25]$. It is found that the surface area and pore volume vary depending on the Mn dosage. The pure CNF exhibits a BET specific surface area of $1234 \mathrm{~m}^{2} \mathrm{~g}^{-1}$ and a total pore volume of $0.916 \mathrm{~cm}^{3} \mathrm{~g}^{-1}$, lower than those of $\mathrm{MnO}_{\mathrm{n}}-\mathrm{CNF}$ composites (Table S1). This implies that the introduction of Mn species facilitates the improvement of pore structure. The porous parameters are Mn dosage dependent. When increasing the Mn dosage from 0.09 to $1.36 \mathrm{wt} \%$, the surface area and pore volume decrease from $1507 \mathrm{~m}^{2} \mathrm{~g}^{-1}$ and $1.129 \mathrm{~cm}^{3} \mathrm{~g}^{-1}$ for $0.025 \mathrm{MnO}_{\mathrm{n}}-\mathrm{CNF}$ to $1366 \mathrm{~m}^{2} \mathrm{~g}^{-1}$ and $0.961 \mathrm{~cm}^{3} \mathrm{~g}^{-1}$ for $0.500 \mathrm{MnO}_{\mathrm{n}}-\mathrm{CNF}$ (Table S1). In spite of this, it is noteworthy to mention that our fabricated $\mathrm{MnO}_{\mathrm{n}}-\mathrm{CNF}$ composites exhibit the extremely high surface area and porosity, nearly 10 times of those reported [9-13]. Moreover, all $\mathrm{MnO}_{\mathrm{n}}-\mathrm{CNF}$ composites show a similar pore size around $4.0 \mathrm{~nm}$ (Fig. 7B), implying that the manganese oxides are mainly inserted into the carbonaceous network, corresponding to a tight contact. According to these findings, large surface area, high porosity and uniform mesopores are integrated in $\mathrm{MnO}_{\mathrm{n}}-\mathrm{CNF}$ composites, which are expected to be beneficial to the adsorption and diffusion of electrolyte ions.

\subsection{Capacitive performance}

To explore the energy-storage application of the $\mathrm{MnO}_{\mathrm{n}}-\mathrm{CNF}$ composite, the sample was fabricated into a supercapacitor electrode, and the performance was evaluated using cyclic voltammetry (CV) and galvanostatic charge-discharge (GCD) measurements. Fig. 8 a shows the $\mathrm{CV}$ curves of various samples at a scan rate of $1 \mathrm{mV}$ $\mathrm{s}^{-1}$. The quasi-rectangular shapes at potential window ranging from 0 to $-1.0 \mathrm{~V}$ were observed, suggesting an ideal pseudocapacitive behavior [26]. The absence of redox 
peaks suggests that the supercapacitor is charged-discharged at a pseudo-constant rate over the complete voltammetric cycle [4]. The gravimetric specific capacitance is proportional to the integrated $\mathrm{CV}$ area. The $0.100 \mathrm{MnO}_{\mathrm{n}}-\mathrm{CNF}$ composite exhibits a higher specific capacitance of up to $179 \mathrm{~F} \mathrm{~g}^{-1}$, while $\mathrm{CNF}, 0.025 \mathrm{MnO}_{\mathrm{n}}-\mathrm{CNF}$, $0.050 \mathrm{MnO}_{\mathrm{n}}-\mathrm{CNF}$ and $0.500 \mathrm{MnO}_{\mathrm{n}}-\mathrm{CNF}$ have a lower specific capacitance of 116,140 , 158 and $142 \mathrm{~F} \mathrm{~g}^{-1}$, respectively. This strongly suggests the important role of $\mathrm{Mn}$ dosage in the capacitance enhancement. Compared to $0.100 \mathrm{MnO}_{\mathrm{n}}-\mathrm{CNF}$, the post-synthetic $0.100 \mathrm{MnO}_{\mathrm{n}}-\mathrm{CNF}-\mathrm{p}$ and mechanically mixed $0.100 \mathrm{MnO}_{2}+\mathrm{CNF}$ exhibit a much lower specific capacitance of 134 and $114 \mathrm{~F} \mathrm{~g}^{-1}$, respectively. The superior dispersion of manganese oxides realized by in situ synthesis should be responsible for a larger capacitance. The pseudo-capacitance based on manganese(IV) oxide $\left(\mathrm{C}_{\mathrm{MnO} 2}\right)$, calculated based on the literature method [27,28], increases from $16501 \mathrm{~F} \mathrm{~g}^{-1}$ for $0.025 \mathrm{MnO}_{\mathrm{n}}-\mathrm{CNF}$ to $18290 \mathrm{~F} \mathrm{~g}^{-1}$ for $0.050 \mathrm{MnO}_{\mathrm{n}}-\mathrm{CNF}$, and then decreases to $1329 \mathrm{~F}$ $\mathrm{g}^{-1}$ for $0.500 \mathrm{MnO}_{\mathrm{n}}-\mathrm{CNF}$ (Table S2). The largest pseudo-capacitance of any $\mathrm{MnO}_{\mathrm{n}}$-based materials was achieved in this study $[4,18,26]$, nearly 14 times of the theoretical specific capacitance of manganese(IV) oxide $\left(1370 \mathrm{~F} \mathrm{~g}^{-1}\right)$. The highly dispersed $\mathrm{MnO}_{\mathrm{n}}$ can be fully utilized due to their ultra-small size and extremely low loading. And thus in such a hybrid configuration, manganese oxides offer an extremely high specific capacitance.

To further investigate the capacitive performance of our samples, galvanostatic charge-discharge (GCD) experiments were performed a current density of $0.25 \mathrm{~A} \mathrm{~g}^{-1}$ (Fig. 8b). These curves are linear and symmetric, implying good reversibility and high 
charge-discharge efficiency. The discharge time of $0.100 \mathrm{MnO}_{\mathrm{n}}-\mathrm{CNF}$ is significantly increased as compared to other composites, corresponding to a larger charge capacity. The change of capacitance based on the GCD curves is consistent with that from the cyclic voltammograms (Table S3). Figure S3 shows the GCD curves of $0.100 \mathrm{MnO}_{\mathrm{n}}-\mathrm{CNF}$ at different current densities. The potential-time profiles maintain a triangular shape even at a high current density, implying that the $0.100 \mathrm{MnO}_{\mathrm{n}}-\mathrm{CNF}$ is suitable for applications in supercapacitors in which the rapid charge-discharge is required.

The superior $0.100 \mathrm{MnO}_{\mathrm{n}}-\mathrm{CNF}$ was then subjected to further $\mathrm{CV}$ investigation under different scan rates. As shown in Fig. 8c, the specific capacitance decreases by $40 \%$ (from 179 to $108 \mathrm{~F} \mathrm{~g}^{-1}$ ) as the sweep rate increases from 1 to $100 \mathrm{mV} \mathrm{s}^{-1}$, indicating the excellent mesoporosity. The $0.100 \mathrm{MnO}_{\mathrm{n}}-\mathrm{CNF}$ composite shows a large surface area and a uniform mesopore size distribution. These properties have allowed a high rate of solution infiltration and facilitated the ion insertion/extraction and electron transportation. The relationship between the capacitance retention ratio and potential scan rate is plotted (Fig. 8d). The minimized capacitance at high scan rate originates from the decreased ion accessible surface areas. The higher the capacitance retention ratio is, the better the ion transport behavior will be. The capacitance retention ratios at $100 \mathrm{mV} \mathrm{s}^{-1}$ are above $60 \%$ for both pure $\mathrm{CNF}$ and $\mathrm{MnO}_{\mathrm{n}}-\mathrm{CNF}$ composites, suggesting that such a high capacitance can be maintained under very high power operation.

Electrochemical impedance spectroscopy (EIS) provides important information 
about the interfacial properties of electrodes, which was used to examine their conductive and diffusion behavior. The equivalent circuit fitting of the Nyquist plot of $0.100 \mathrm{MnO}_{\mathrm{n}}-\mathrm{CNF}$ is shown in Fig. 9a. The slope of the curves at a low frequency is called Warburg impedancue (W), which is induced by ion diffusion/transport from the electrolyte to the electrode surface. The low-frequency segment of the impedance spectrum was nearly vertical except for $\mathrm{CNF}$ and $0.050 \mathrm{MnO}_{\mathrm{n}}-\mathrm{CNF}$, indicating ideal capacitor behavior. The semicircular part in the higher frequency corresponds to the charge transfer at the electrode/electrolyte interface, and its diameter is equivalent to the Faradaic charge transfer resistance $\left(\mathrm{R}_{\mathrm{ct}}\right)$. Comparing the Nyquist plots of various samples (Fig. 9b), it is clear that $0.025 \mathrm{MnO}_{\mathrm{n}}-\mathrm{CNF}, 0.050 \mathrm{MnO}_{\mathrm{n}}-\mathrm{CNF}$ and $0.100 \mathrm{MnO}_{\mathrm{n}}-\mathrm{CNF}$ show a smaller diameter of semicircle as compared to $0.500 \mathrm{MnO}_{\mathrm{n}}-\mathrm{CNF}$, implying a higher conductivity was achieved. Solution resistance $\left(R_{s}\right)$ is the intersection of the curve at real part $Z^{\prime}$. It is a combinational resistance of ionic resistance of electrolyte, intrinsic resistance of substrate, and contact resistance between electrode and current collector. Considering that the same electrolyte, current collector and assembling technique for the electrode were used during the test, the intercept shown in the high frequency semicircle essentially reveals the conductivity of $\mathrm{MnO}_{\mathrm{n}}$-CNF composites. Correspondingly, the solution resistance ranges from 0.45 to $0.52 \Omega$, smaller than that $\left(0.73 \Omega\right.$ ) of $0.500 \mathrm{MnO}_{\mathrm{n}}-\mathrm{CNF}$ (Fig. $9 \mathrm{~b}$, inset), confirming the superior conductivity. The conductance of $\mathrm{MnO}_{\mathrm{n}}-\mathrm{CNF}$ electrode material decays faster at Mn levels greater than $0.39 \mathrm{wt} \%$. Excess introduction of metal oxides erodes the composite conductivity, which agrees with that reported for $\mathrm{V}_{2} \mathrm{O}_{5}$ film/carbon 
nanofiber paper electrode [28].

The cycling stability of $0.100 \mathrm{MnO}_{\mathrm{n}}-\mathrm{CNF}$ was examined at a current density of 5 $\mathrm{A} \mathrm{g}^{-1}$ (Fig. 9c). The capacitance remains almost constant with a slight fluctuation, and $98 \%$ of the initial capacitance $\left(149 \mathrm{~F} \mathrm{~g}^{-1}\right)$ is retained when cycling up to 5000 cycles. The fading rate is only $0.00071 \%$ per cycle, which makes the $\mathrm{MnO}_{\mathrm{n}}-\mathrm{CNF}$ composite highly stable during the repeated charge-discharge process. Such a high stability can be ascribed to the tight contact between manganese oxides and carbon nanofibers rendered by in situ synthesis. The cycling performance of $0.100 \mathrm{MnO}_{\mathrm{n}}-\mathrm{CNF}$ is much better than those of previously reported $\mathrm{MnO}_{2}-\mathrm{NiO}$ hybrid array $(12 \%$ loss after 1500 cycles) [29], $\mathrm{MnO}_{2}$ coaxially coated on a CNT array (decreased by ca. $11 \%$ after only 500 cycles) [30], and electrodeposited $\mathrm{MnO}_{2}$ film (13\% loss after 2000 cycles) [31].

In order to completely determine the electrochemical performance of our materials, energy density and power density were further estimated. The Ragone plot for the $0.100 \mathrm{MnO}_{\mathrm{n}}-\mathrm{CNF}$ capacitor in $6 \mathrm{M} \mathrm{KOH}$ is presented in Fig. $9 \mathrm{~d}$, showing that the specific energy density is about $19.7 \mathrm{Wh} \mathrm{kg}^{-1}$ at a current density of $0.25 \mathrm{~A} \mathrm{~g} \mathrm{~g}^{-1}$, even orders higher than those of reported electric double-layer capacitors and pseudocapacitors $[32,33]$. It is noteworthy to mention that specific energy still is 17.0 Wh kg-1 at a high current density of $2 \mathrm{~A} \mathrm{~g}^{-1}$. The power density is $0.89 \mathrm{~kW} \mathrm{~kg}^{-1}$ at a current density of $2 \mathrm{~A} \mathrm{~g} \mathrm{~g}^{-1}$, comparable to or higher than high-end commercially available supercapacitors [34]. All the above results clearly reveal the exceptional capability of the $0.100 \mathrm{MnO}_{\mathrm{n}}-\mathrm{CNF}$ electrode to meet the requirements for high capacitance, good rate capability and long cycling life, which are crucial factors for 
high-performance energy-storage devices.

\section{Conclusions}

In summary, ultrafine manganese oxide-decorated carbon nanofibers have been successfully developed by skillful construction and evolution of Mn, Zn-containing metal organic framework fibers. This facile and economic synthesis renders ultrafine manganese oxides, which are evenly dispersed, and are firmly inserted into the porous carbon nanofibers formed simutaneously. Some merits, such as easy accessibility, high porosity, tight contact and superior conductivity, are integrated in final $\mathrm{MnO}_{\mathrm{n}}-\mathrm{CNF}$ composites. And thus a remarkable specific capacitance up to $18290 \mathrm{~F} \mathrm{~g}^{-1}$ of per mass of $\mathrm{MnO}_{2}$, and an excellent cycling up to 5000 times, as well as a high energy density of $19.7 \mathrm{Wh} \mathrm{kg}^{-1}$ have been achieved using such $\mathrm{MnO}_{\mathrm{n}}-\mathrm{CNF}$ composites. Therefore, supercapacitors based on this novel hybrid composite are of low cost but high performance, which would accelerate their adoption in practical applications.

\section{Acknowledgements}

The authors gratefully acknowledge financial support from the National Natural Science Foundation of China $(21303229,21173269,51471187)$, Beijing Natural Science Foundation $(2152025,2152026)$, the Science Foundation of China University of Petroleum, Beijing (2462013YJRC018, 2462013YJRC005 ), and the State Key Lab of Advanced Metals and Materials 2014-ZD01. Use of the Advanced Photon Source, an Office of Science User Facility operated for the U.S. Department of Energy (DOE)

Office of Science by Argonne National Laboratory, supported by the U.S. DOE under Contract No. DE-AC02-06CH11357, is also acknowledged. 


\section{References}

[1] Wei WF, Cui XW, Chen WX, Ivey DG. Manganese oxide-based materials as electrochemical supercapacitor electrodes. Chem Soc Rev 2011; 40: 1697-1721.

[2] Wang GP, Zhang L, Zhang JJ. A review of electrode materials for electrochemical supercapacitors. Chem Soc Rev 2012; 41: 797-828.

[3] Chen S, Xing W, Duan JJ, Hu XJ, Qiao SZ. Nanostructured morphology control for efficient supercapacitor electrodes. J Mater Chem A 2013; 1: 2941-2954.

[4] Liu MX, Gan LH, Xiong W, Xu ZJ, Zhu DZ, Chen LW. Development of $\mathrm{MnO}_{2} /$ porous carbon microspheres with a partially graphitic structure for high performance supercapacitor electrodes. J Mater Chem A 2014; 2: 2555-2562.

[5] Zhang B, Yu Y, Huang ZD, He Y-B, Jang D, Yoon W-S, et al. Exceptional electrochemical performance of freestanding electrospun carbon nanofiber anodes containing ultrafine $\mathrm{SnO}_{\mathrm{x}}$ particles. Energy Environ Sci 2012; 5: 9895-9902.

[6] Singh S, Verma N. Fabrication of Ni nanoparticles-dispersed carbon micro-nanofibers as the electrodes of a microbial fuel cell for bio-energy production. Int J Hydrogen Energy 2015; 40: 1145-1153.

[7] Zheng J-S, Wang M-X, Zhang X-S, Wu Y-X, Li P, Zhou X-G, et al. Platinum/carbon nanofiber nanocomposite synthesized by electrophoretic deposition as electrocatalyst for oxygen reduction. J Power Sources 2008; 175: 211-216.

[8] Yang L, Cheng S, Ding Y, Zhu XB, Wang ZL, Liu ML. Hierarchical network 
architectures of carbon fiber paper supported cobalt oxide nanonet for high-capacity pseudocapacitors. Nano Lett 2012; 12: 321-325.

[9] Lee J, Jo C, Park B, Hwang W, Lee HI, Yoond S, et al. Simple fabrication of flexible electrodes with high metal-oxide content: electrospun reduced tungsten oxide/carbon nanofibers for lithium ion battery applications. Nanoscale 2014; 6: 10147-10155.

[10] Guo QH, Liu D, Zhang XP, Li LB, Hou, HQ Niwa O, et al. Pd-Ni alloy nanoparticle/carbon nanofiber composites: preparation, structure, and superior electrocatalytic properties for sugar analysis. Anal Chem 2014; 86: 5898-5905.

[11] Kim B-H. Supercapacitive properties of nanoporous carbon nanofibers developed from polyacrylonitrile and tetraethyl orthosilicate. J Electroanal Chem 2014; 734: 84-89.

[12] Wang HQ, Zhang CF, Chen ZX, Liu HK, Guo ZP. Large-scale synthesis of ordered mesoporous carbon fiber and its application as cathode material for lithium-sulfur batteries. Carbon 2015; 81: 782-787.

[13] Dong Y, Lin HM, Jin QM, Li L, Wang D, Zhou D, et al. Synthesis of mesoporous carbon fibers with a high adsorption capacity for bulky dye molecules. J Mater Chem A 2013; 1: 7391-7398.

[14] Xie LH, Liu SX, Gao B, Zhang CD, Sun CY, Li DH, et al. A Three-dimensional porous metal-organic framework with the rutile topology constructed from triangular and distorted octahedral building blocks. Chem Commun 2005; $2402-2404$. 
[15] Jiang J, Zhu JH, Ai W, Fan ZX, Shen XN, Zou CJ, et al. Evolution of disposable bamboo chopsticks into uniform carbon fibers: a smart strategy to fabricate sustainable anodes for Li-ion batteries. Energy Environ Sci 2014; 7: 2670-2679.

[16] Fang LX, Zhang BL, Li W, Li XJ, Xin TJ, et al. Controllable synthesis of ZnO hierarchical architectures and their photocatalytic property. Superlattices Microstruct $2014 ; 75: 324-333$.

[17] Banerjee R, Sperling EA, Thompson GB, Fraser HL. Lattice expansion in nanocrystalline niobium thin films. Appl Phys Lett 2003; 82: 4250-4252.

[18] Jiang H, Yang LP, Li CZ, Yan CY, Lee PS, Ma J. High-rate electrochemical capacitors from highly graphitic carbon-tipped manganese oxide/mesoporous carbon/manganese oxide hybrid nanowires. Energy Environ Sci 2011; 4: 1813-1819.

[19] Wu ZX, Lv YY, Xia YY, Webley PA, Zhao DY. Ordered mesoporous platinum@graphitic carbon embedded nanophase as a highly active, stable, and methanol-tolerant oxygen reduction electrocatalyst. J Am Chem Soc 2012; 134 : 2236-2245.

[20] Radhakrishnan L, Reboul J, Furukawa S, Srinivasu P, Kitagawa S, Yamauchi Y. Preparation of microporous carbon fibers through carbonization of Al-based porous coordination polymer (Al-PCP) with furfuryl alcohol. Chem Mater 2011; 23: $1225-1231$.

[21] Qiao BT, Wang AQ, Yang XF, Allard LF, Jiang Z, Cui YT, et al. Single-atom catalysis of $\mathrm{CO}$ oxidation using $\mathrm{Pt}_{1} / \mathrm{FeO}_{\mathrm{x}}$. Nat Chem 2011; 3: 634-641. 
[22] Nam K-W, Kim MG, Kim K-B. In situ Mn K-edge X-ray absorption spectroscopy studies of electrodeposited manganese oxide films for electrochemical capacitors. J Phys Chem C 2007; 111: 749-758.

[23] Chaikittisilp W, Hu M, Wang HJ, Huang H-S, Fujita T, Wu KC-W, et al. Nanoporous carbons through direct carbonization of a zeolitic imidazolate framework for supercapacitor electrodes. Chem Commun 2012; 48:7259-7261.

[24] Kruk M, Jaroniec M. Gas adsorption characterization of ordered organic-inorganic nanocomposite materials. Chem Mater 2001; 13: 3169-3183.

[25] Rouquerol J, Avnir D, Fairbridge CW, Everett DH, Haynes JH, Pernicone N, et al. Recommendations for the characterization of porous solids. Pure Appl Chem 1994; 66: 1739-1758.

[26] Huang Y, Li YY, Hu ZQ, Wei GM, Guo JL, Liu JP. A carbon modified $\mathrm{MnO}_{2}$ nanosheet array as a stable high-capacitance supercapacitor electrode. J Mater Chem A 2013; 1: 9809-9813.

[27] Mao L, Zhang K, Chan HSO, Wu JS, Nanostructured $\mathrm{MnO}_{2}$ /graphene composites for supercapacitor electrodes: the effect of morphology, crystallinity and composition. J Mater Chem 2012; 22: 1845-1851.

[28] Ghosh A, Ra EJ, Jin MH, Jeong H-K, Kim TH, Biswas C, et al. High pseudocapacitance from ultrathin $\mathrm{V}_{2} \mathrm{O}_{5}$ films electrodeposited on self-standing carbon-nanofiber paper. Adv Funct Mater 2011; 21: 2541-2547.

[29] Liu JP, Jiang J, Michel B, Fan HJ. Three-dimensional tubular arrays of $\mathrm{MnO}_{2}-\mathrm{NiO}$ nanoflakes with high areal pseudocapacitance. J Mater Chem 2012; 
22: $2419-2426$.

[30] Zhao H, Cao GP, Wang ZY, Yang YS, Shi ZJ, Gu ZN. Growth of manganese oxide nanoflowers on vertically-aligned carbon nanotube arrays for high-rate electrochemical capacitive energy storage. Nano Lett 2008; 8: 2664-2668.

[31] Xiao W, Xia H, Fuh JYH, Lu L. Electrochemical synthesis and supercapacitive properties of $\varepsilon-\mathrm{MnO}_{2}$ with porous/nanoflaky hierarchical architectures. J Electrochem Soc 2009; 156: A627-A633.

[32] Chen L-F, Zhang X-D, Liang H-W, Kong MG, Guan Q-F, Chen P, et al. Synthesis of nitrogen-doped porous carbon nanofibers as an efficient electrode material for supercapacitors. ACS Nano 2012; 8: 7092-7102.

[33] Zhu Y, Murali S, Stoller MD, Ganesh KJ, Cai W, Ferreira PJ, et al. Carbon-based supercapacitors produced by activation of graphene. Science 2011; 332: $1537-1541$.

[34] $\mathrm{Hu}$ J, Wang HL, Gao QM, Guo HL. Porous carbons prepared by using metal-organic framework as the precursor for supercapacitors. Carbon 2010, 48: 3599-3606. 


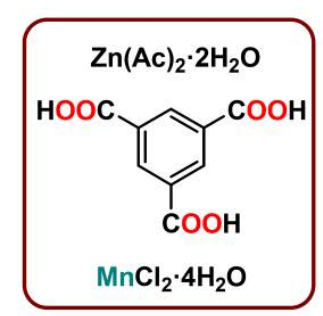

Precursor solution

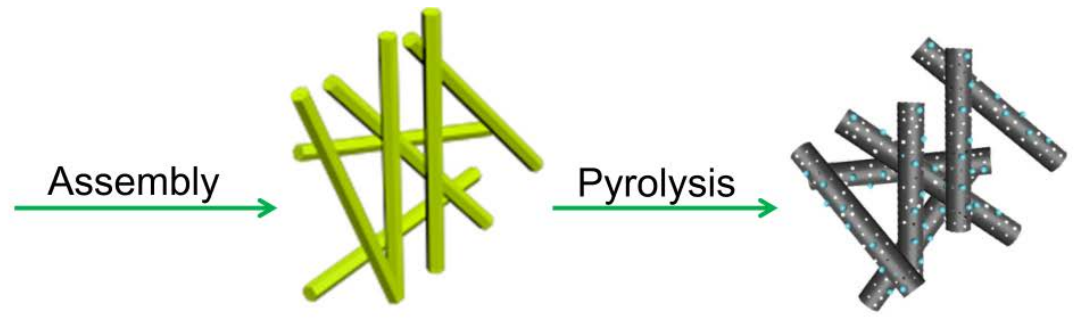

Mn-ZnBTC fiber
$\mathrm{MnO}_{\mathrm{n}}-\mathrm{CNF}$ composite

Fig. 1. Illustration of the $\mathrm{MnO}_{\mathrm{n}}-\mathrm{CNF}$ fabrication process. 


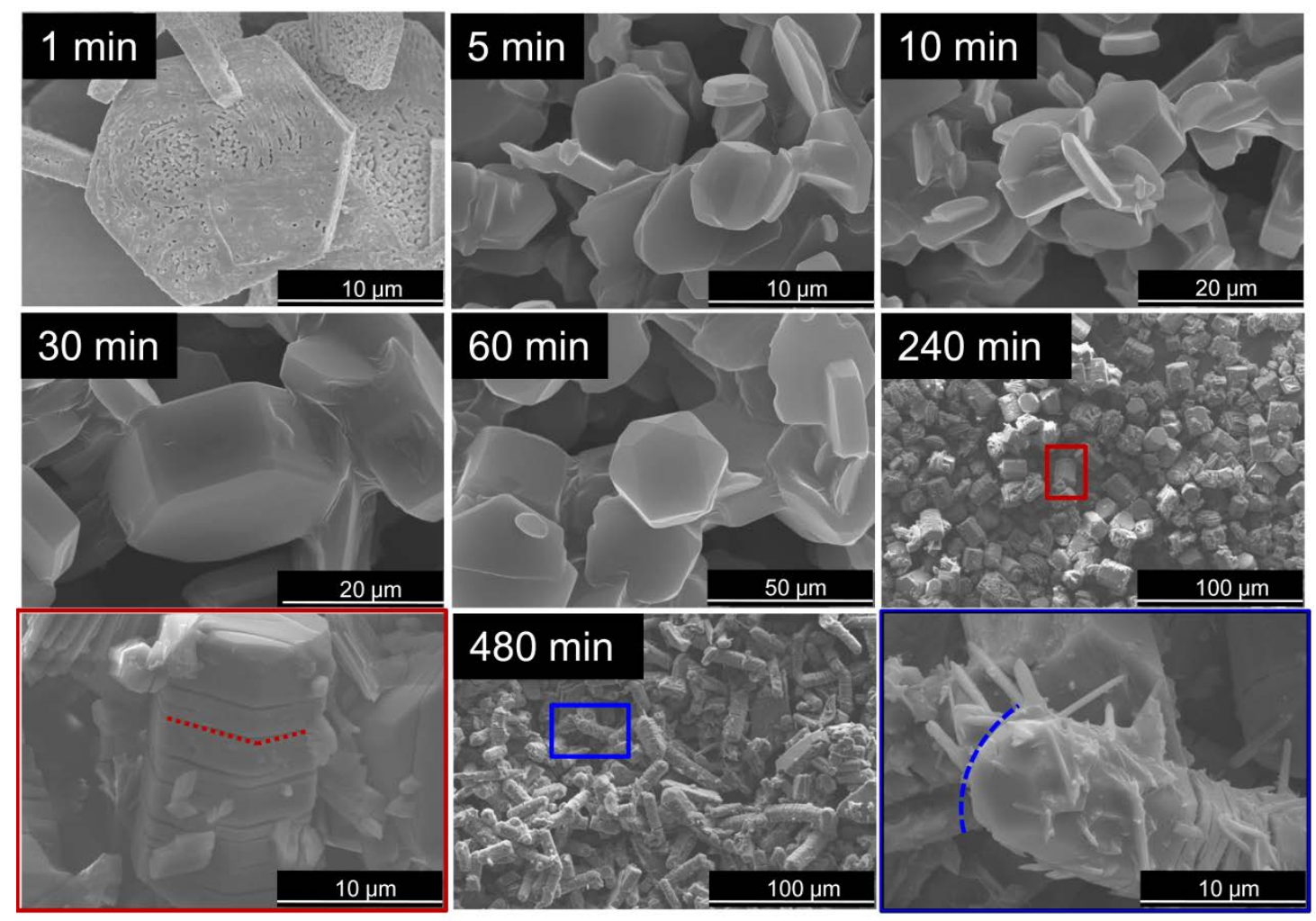

Fig. 2. High-resolution SEM images of 0.100Mn-ZnBTC synthesized at different reaction time. 

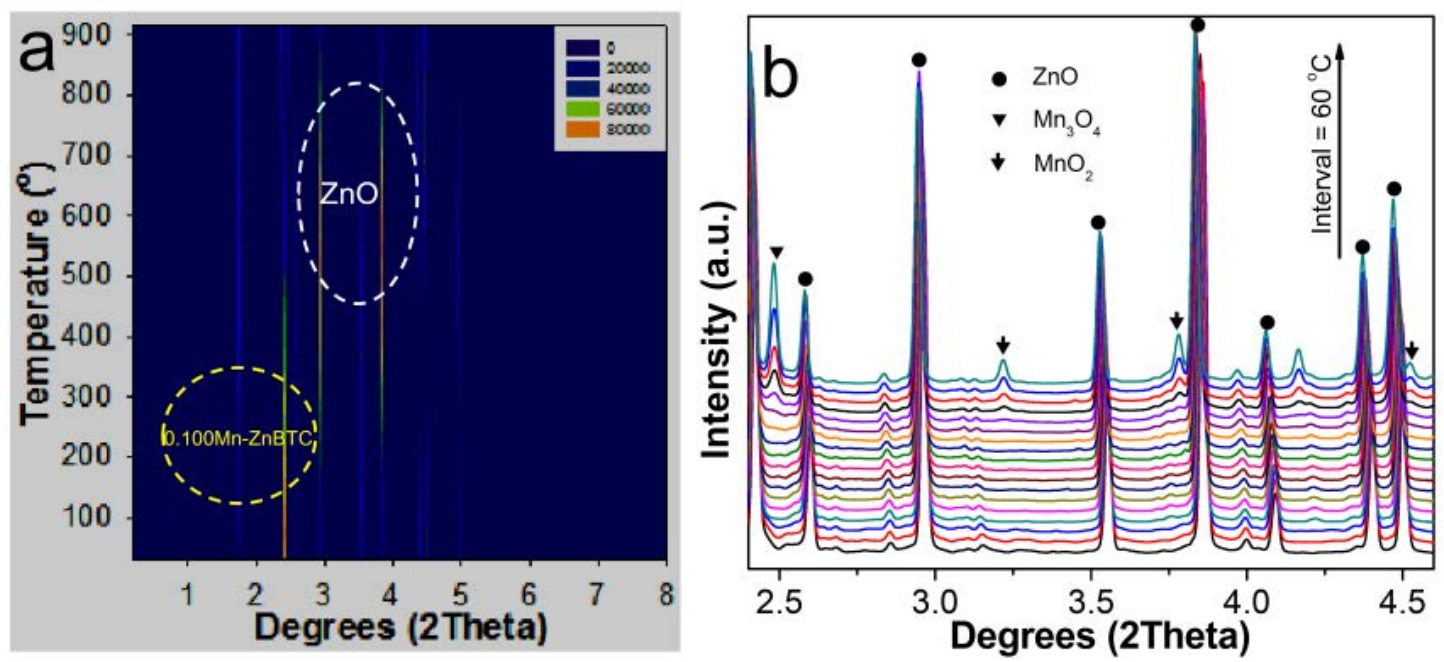

Fig. 3. (a) Contour map of the temporal in situ synchrotron high energy X-ray diffraction patterns recorded by pyrolysis of $0.100 \mathrm{Mn}-\mathrm{ZnBTC}$ in temperature range of 30-950 ${ }^{\circ} \mathrm{C}$ with a ramp rate of $5{ }^{\circ} \mathrm{C} \mathrm{min}^{-1}$ in Ar atmosphere, and (b) the corresponding high energy X-ray diffraction patterns. 


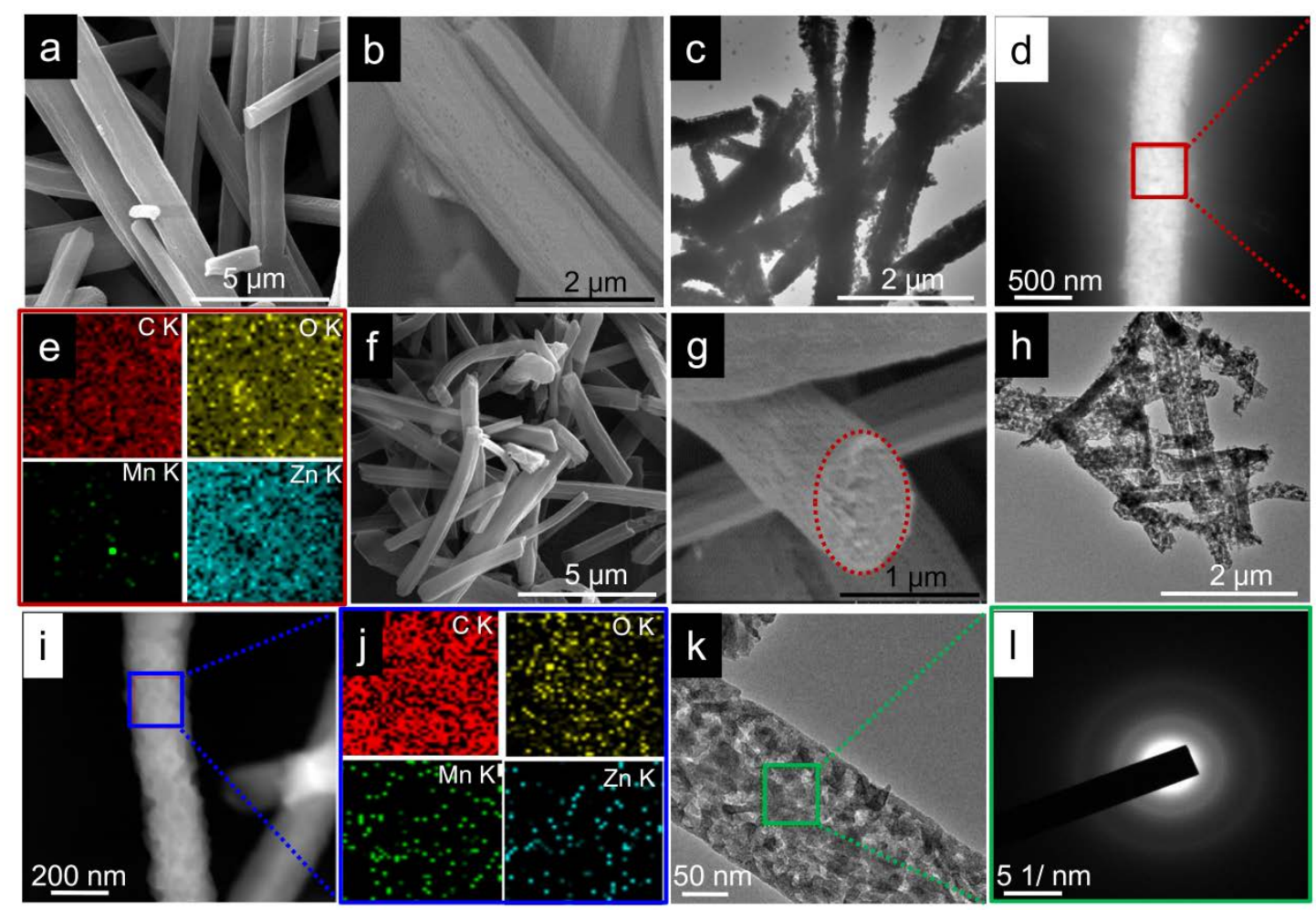

Fig. 4. (a) SEM image and (b) the corresponding high-resolution SEM image, (c)

TEM image, (d) HAADF-STEM image and (e) elemental maps of 0.100Mn-ZnBTC;

(f) SEM image and (g) the corresponding high-resolution SEM image, (h) TEM image, (i) HAADF-STEM image and (j) elemental maps of $0.100 \mathrm{MnO}_{\mathrm{n}}-\mathrm{CNF}$; (k) the enlarged image for a single nanofiber shown in (h); and (l) SAED pattern of $0.100 \mathrm{MnO}_{\mathrm{n}}-\mathrm{CNF}$. 

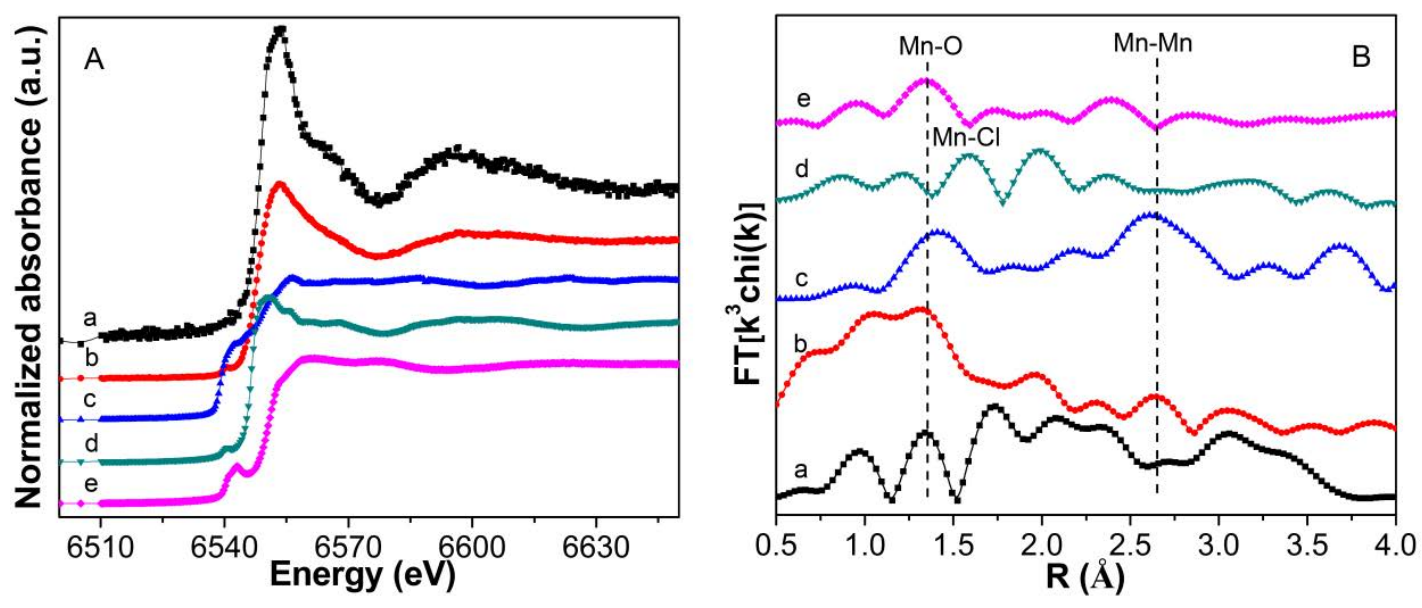

Fig. 5. (A) Mn K-edge XANES and (B) Mn K-edge EXAFS of (a) 0.100Mn-ZnBTC, (b) $0.100 \mathrm{MnO}_{\mathrm{n}}-\mathrm{CNF}$, (c) $\mathrm{Mn}$ foil, (d) $\mathrm{MnCl}_{2} \cdot 4 \mathrm{H}_{2} \mathrm{O}$ and (e) $\mathrm{MnO}_{2}$. 


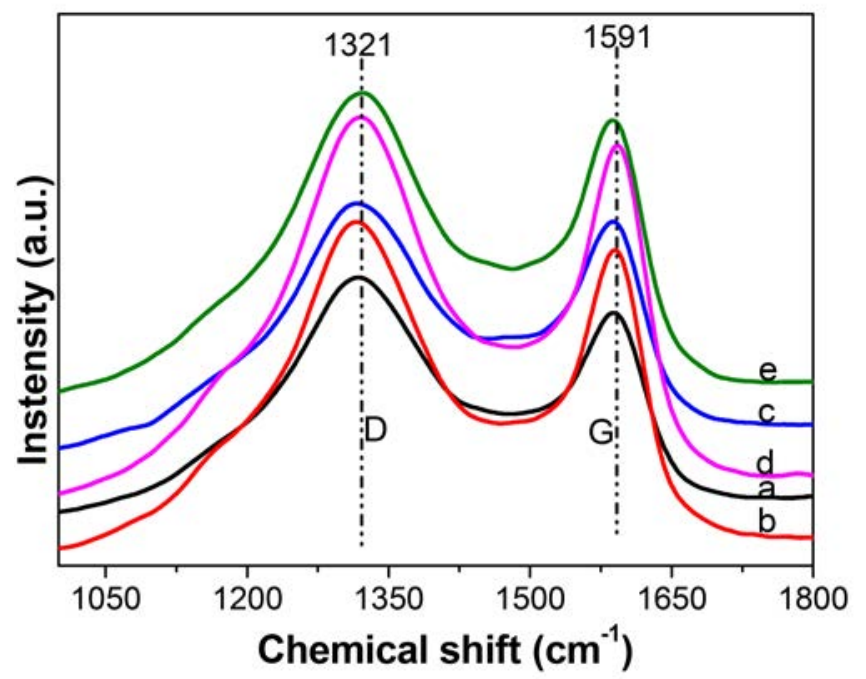

Fig. 6. Raman spectra of (a) CNF, (b) $0.025 \mathrm{MnO}_{\mathrm{n}}-\mathrm{CNF}$, (c) $0.050 \mathrm{MnO}_{\mathrm{n}}-\mathrm{CNF}$, (d) $0.100 \mathrm{MnO}_{\mathrm{n}}-\mathrm{CNF}$ and (e) $0.500 \mathrm{MnO}_{\mathrm{n}}-\mathrm{CNF}$. 

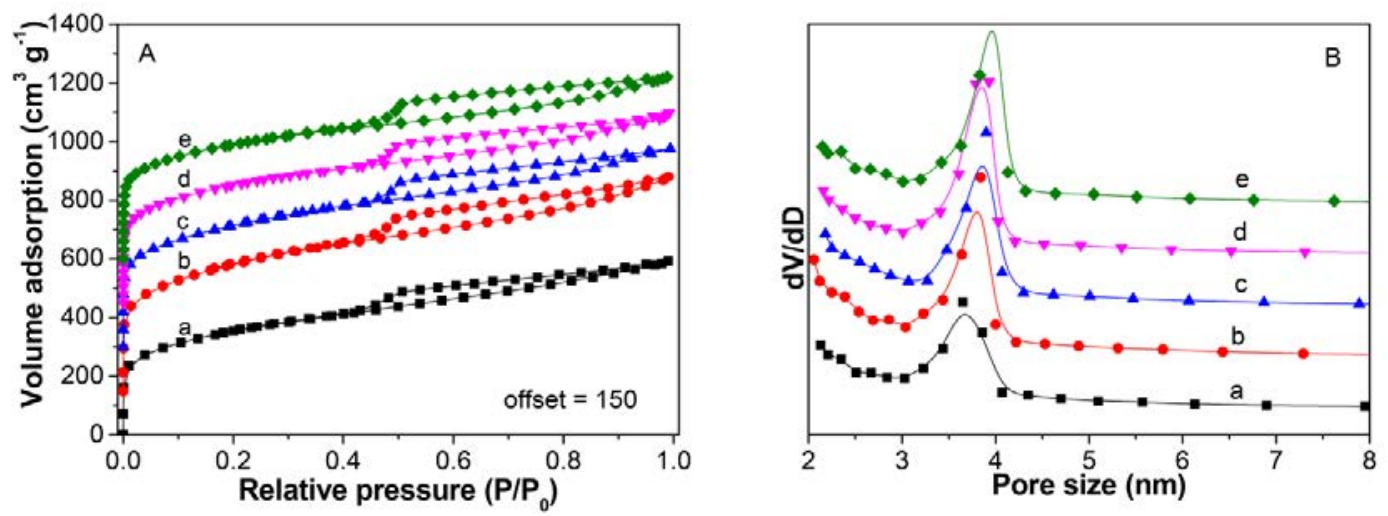

Fig. 7. (A) $\mathrm{N}_{2}$ adsorption/desorption isotherms and (B) the corresponding pore size distribution curves of (a) CNF, (b) $0.025 \mathrm{MnO}_{\mathrm{n}}-\mathrm{CNF}$, (c) $0.050 \mathrm{MnO}_{\mathrm{n}}-\mathrm{CNF}$, (d) $0.100 \mathrm{MnO}_{\mathrm{n}}-\mathrm{CNF}$ and (e) $0.500 \mathrm{MnO}_{\mathrm{n}}-\mathrm{CNF}$. 

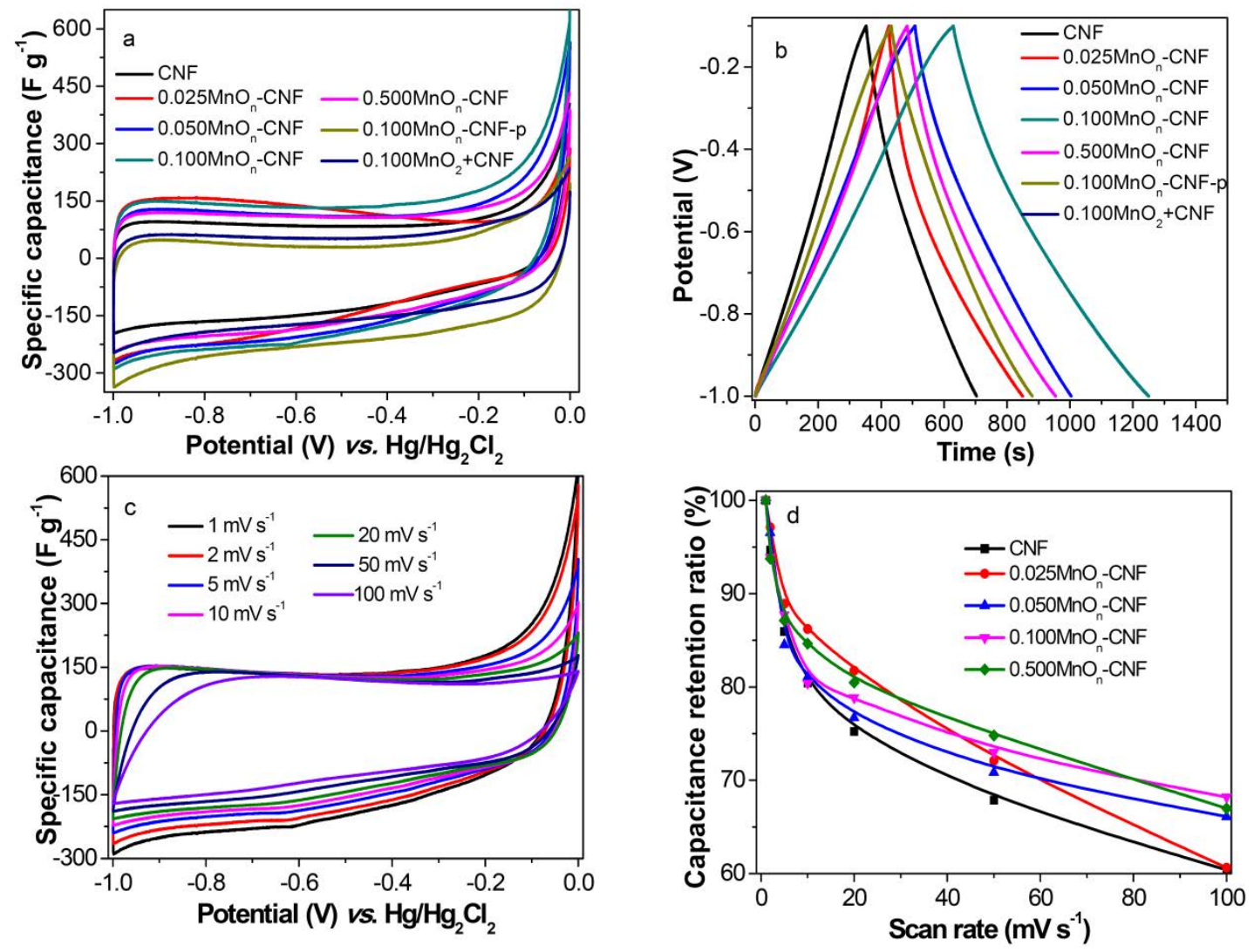

Fig. 8. Capacitive performance: (a) $\mathrm{CV}$ curves at $1 \mathrm{mV} \mathrm{s}^{-1}$, (b) galvanostatic charge-discharge curves at $0.25 \mathrm{~A} \mathrm{~g}^{-1}$, (c) $\mathrm{CV}$ curves at different scans for $0.100 \mathrm{MnO}_{\mathrm{n}}-\mathrm{CNF}$ and (d) capacitance retention ratios as a function of scan rates in 6 M KOH. 

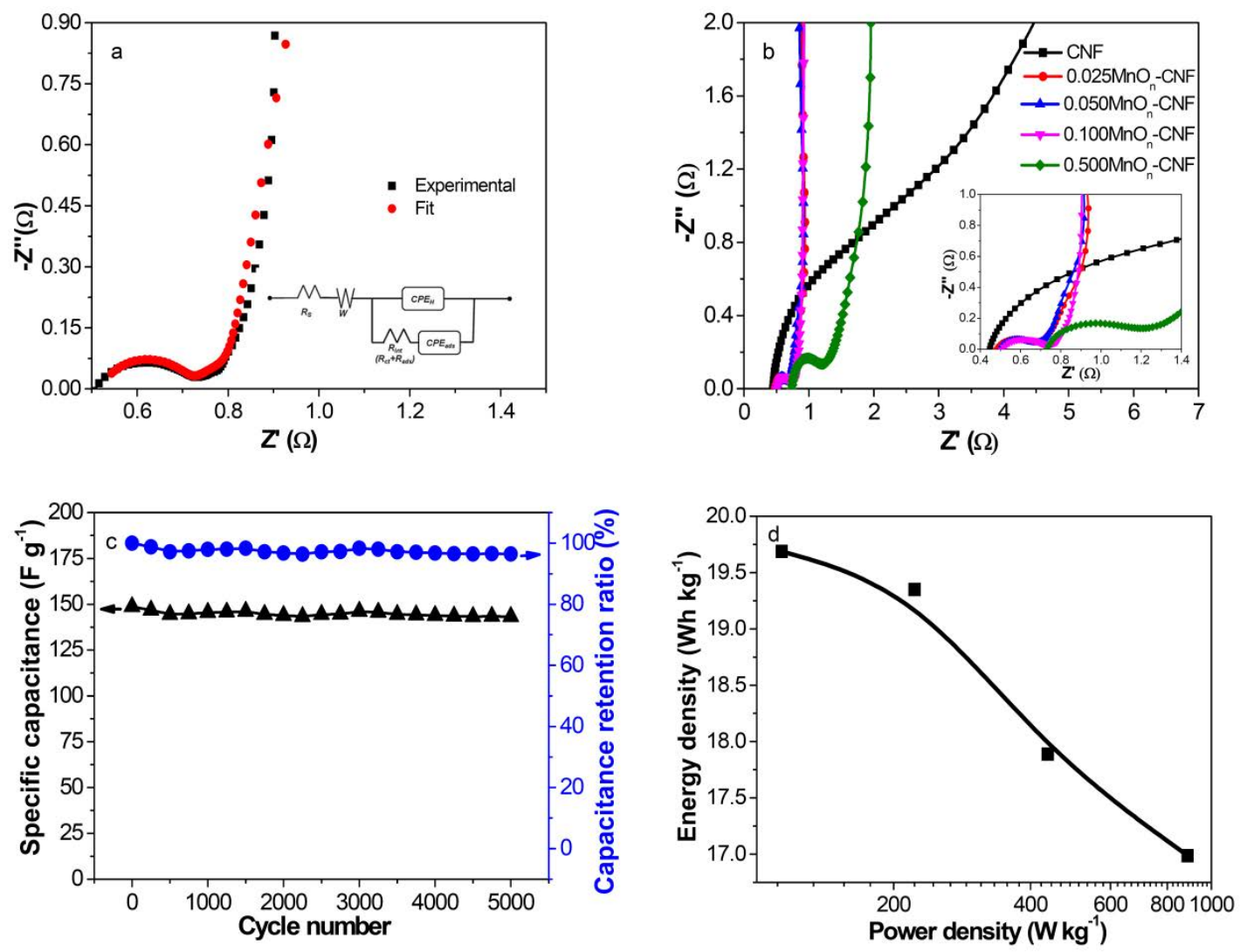

Fig. 9. Capacitive performance: (a) measured and simulated EIS impedance for $0.100 \mathrm{MnO}_{\mathrm{n}}-\mathrm{CNF}$, and the equivalent electrical circuit (inset), (b) Nyquist plots, (c) cycling durability of $0.100 \mathrm{MnO}_{\mathrm{n}}-\mathrm{CNF}$, and (d) Ragone plot performed in $6.0 \mathrm{M}$ of $\mathrm{KOH}$ aqueous solution for $0.100 \mathrm{MnO}_{\mathrm{n}}-\mathrm{CNF}$. 


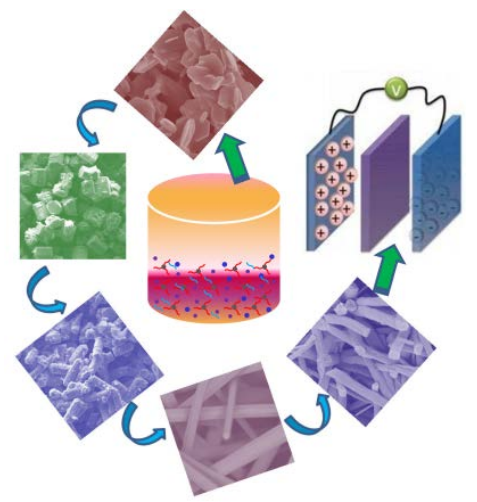

Morphology controlled synthesis of Mn, Zn-containing metal organic framework fibers was carried out by varying the assembly time. Such a fiber precursor was converted to a new type of ultrafine manganese oxide-decorated carbon nanofiber upon pyrolyzed. This synthesis integrates excellent accessibility, high porosity, tight contact and superior conductivity in the final products, and thus exhibits a remarkable capacitance of up to $18290 \mathrm{~F} \mathrm{~g}^{-1}$ per active mass of the manganese(IV) oxide, high stability of cycling up to 5000 times, as well as the maximum energy density is up to 19.7 $\mathrm{Wh} \mathrm{kg}^{-1}$ at the current density of $0.25 \mathrm{~A} \mathrm{~g}^{-1}$. 